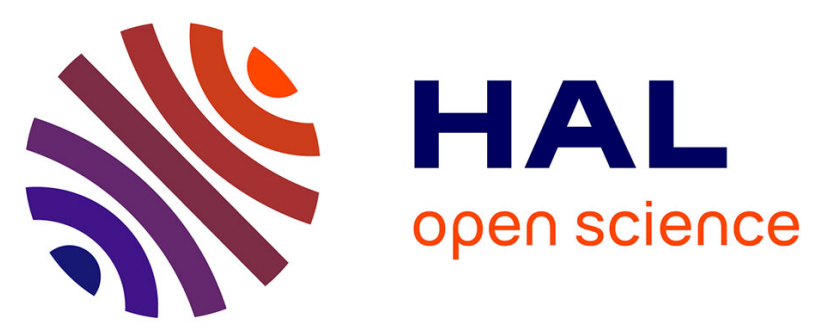

\title{
Characterization of IN-IC integrable in-plane nanometer scale resonators fabricated by a silicon on nothing advanced CMOS technology
}

\author{
Cédric Durand, Fabrice Casset, Bernard Legrand, Marc Faucher, Philippe
} Renaux, Denis Mercier, Denis Renaud, Didier Dutartre, Eric Ollier, Pascal Ancey, et al.

\section{To cite this version:}

Cédric Durand, Fabrice Casset, Bernard Legrand, Marc Faucher, Philippe Renaux, et al.. Characterization of IN-IC integrable in-plane nanometer scale resonators fabricated by a silicon on nothing advanced CMOS technology. 21st IEEE International Conference on Micro Electro Mechanical Systems, MEMS 2008, Jan 2008, Tucson - AZ, United States. pp.1016-1019, 10.1109/MEMSYS.2008.4443831 . cea-00320830

\section{HAL Id: cea-00320830 https://hal-cea.archives-ouvertes.fr/cea-00320830}

Submitted on 20 Sep 2008

HAL is a multi-disciplinary open access archive for the deposit and dissemination of scientific research documents, whether they are published or not. The documents may come from teaching and research institutions in France or abroad, or from public or private research centers.
L'archive ouverte pluridisciplinaire HAL, est destinée au dépôt et à la diffusion de documents scientifiques de niveau recherche, publiés ou non, émanant des établissements d'enseignement et de recherche français ou étrangers, des laboratoires publics ou privés. 


\section{CHARACTERIZATION OF IN-IC INTEGRABLE IN-PLANE NANOMETER SCALE RESONATORS FABRICATED BY A SILICON ON NOTHING ADVANCED CMOS TECHNOLOGY}

C. Durand ${ }^{123}$, F. Casset $^{2}$, B. Legrand ${ }^{3}$, M. Faucher ${ }^{3}$, P. Renaux ${ }^{2}$, D. Mercier ${ }^{2}$, D. Renaud ${ }^{2}$, D. Dutartre E. Ollier ${ }^{2}, P$. Ancey ${ }^{1}$ and L. Buchaillot ${ }^{3}$

${ }^{1}$ STMicroelectronics, Crolles, FRANCE

${ }^{2}$ CEA-LETI MINATEC, Grenoble, FRANCE

${ }^{3}$ IEMN CNRS UMR 8520, Villeneuve d'Ascq, FRANCE

\begin{abstract}
The paper reports on in-plane nanometer scale resonators fabricated on 8 inch industrial tools, with a process based on the advanced CMOS Front End Silicon On Nothing Technology. The aim is to propose totally integrated time reference functions realized by small size NEMS resonators.

The measurement set-up, simulation and experimental results in the range of $100 \mathrm{MHz}$ are presented. Environmental issues such as temperature and pressure influence on the resonator behavior are also investigated.

Results are discussed and compared with analytic calculation, finite element and electrical simulations with good agreement.

Work in progress focuses on improving the $f . Q$ product, detection by the use of integrated MOSFET transistors, low voltage operation and in-IC integration.
\end{abstract}

\section{INTRODUCTION}

Devices are fabricated on 8 inch tools, hence proving the feasibility of MEMS/NEMS with a Front-End process in an industrial clean-room facility. The fabrication is based on a Silicon On Nothing (SON) Technology [1] under development at STMicroelectronics for future CMOS generations. This work paves the way for the very large scale integration (VLSI) of micro-electro-mechanical resonators for RF applications.

The aim in a near future is to be able to replace spaceconsuming functions such as time references made by off chip Quartz oscillators, by small sizes MEMS/NEMS resonators that could be totally integrated in-IC, resulting in cost, consumption and sizes reductions [2].

The paper reports on the fabrication process, measurement set-up, electrical equivalent circuit of the device, and gives experimental results such as devices electrical responses, temperature and pressure behavior.

Analytic calculation, finite element and electrical simulations have been performed and fit well measurement results.

\section{DEVICE FABRICATION}

Devices were fabricated using the SON technology [1], to achieve sub-100nm gaps and $400 \mathrm{~nm}$ thick single-crystal silicon resonators using only pure front-end process [3] and materials, ensuring in-IC integration capability.

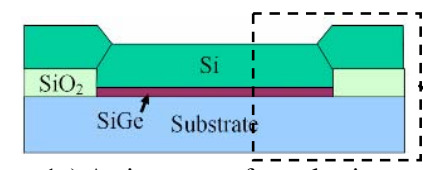

1a) Active areas after selective

SiGe epitaxy followed by a non-

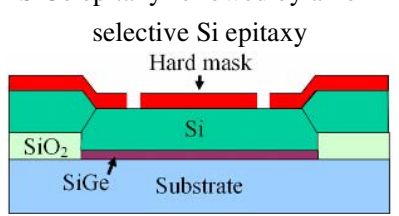

1b) E-beam step leading to a 47 gap resolution

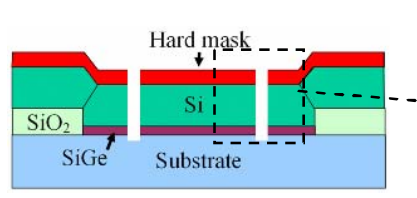

1c) $400 \mathrm{~nm}$ deep and $88 \mathrm{~nm}$ wide air gap after anisotropic dry etching
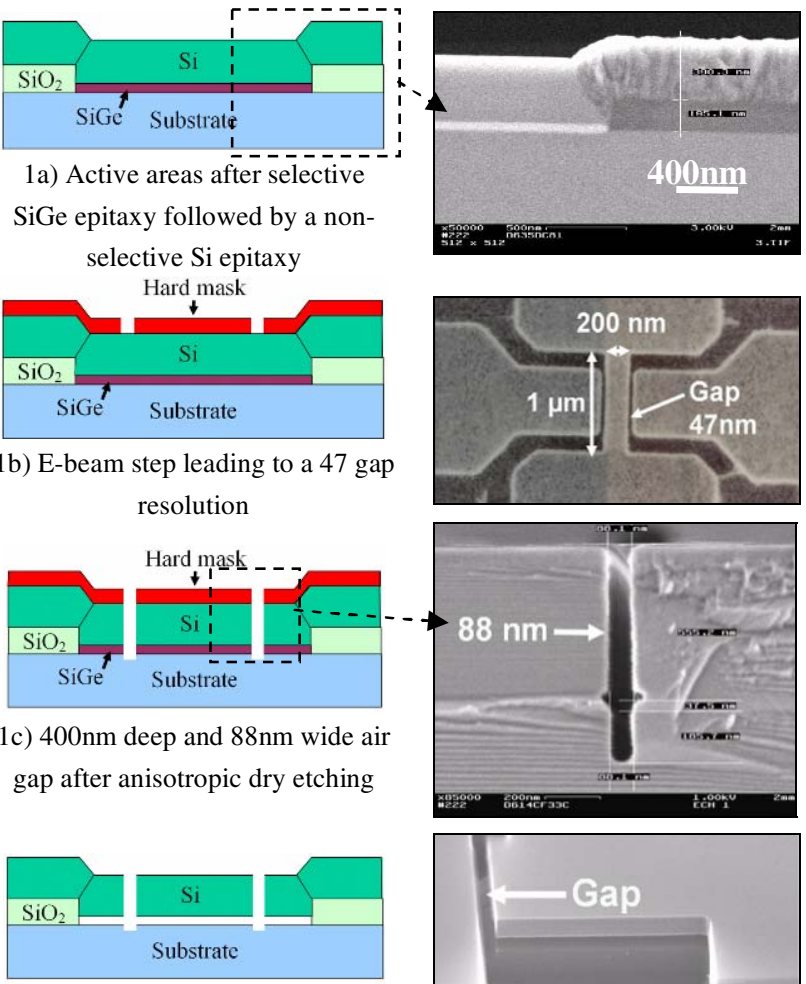

1d) Released silicon structure after SiGe dry isotropic etching

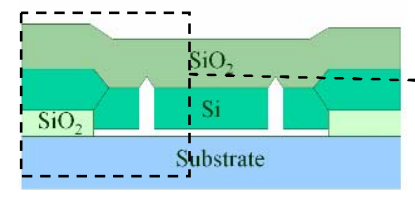

1e) Non-conformal $\mathrm{SiO}_{2}$ deposition as a protection for metallization on

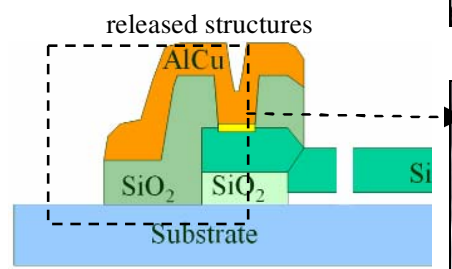

1f) Metallization pads: NiSi silicide and $\mathrm{AlCu}$ stack isolated from the

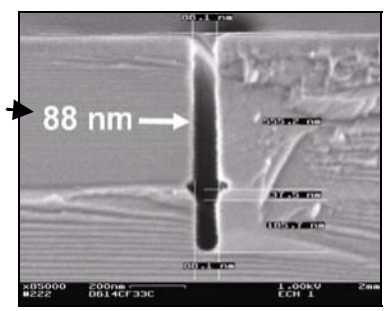

substrate by a thick $\mathrm{SiO}_{2}$

Figure 1: Fabrication process flow and SEM illustrations 
The fabrication process flow presented in Figure 1 starts with the patterning of active areas through a thermal $\mathrm{SiO}_{2}$ layer. A SiGe sacrificial layer is then grown by selective epitaxy, followed by a high boron doped $\left(5.10^{19}\right.$ $\mathrm{at} / \mathrm{cm}^{3}$ ) non-selective single-crystal silicon epitaxy (Figure 1a). E-beam lithography is used to define gaps and the resonator structure leading to a $47 \mathrm{~nm}$ gap resolution (Figure 1b). The $400 \mathrm{~nm}$ thick silicon structural layer is then etched by an anisotropic plasma to define air gaps (Figure 1c). Then structures are released by isotropic plasma etching (Figure 1d). The released structures were protected from the metallization by a non-conformal $\mathrm{SiO}_{2}$ deposition (Figure 1e). Pads are then formed by a NiSi salicidation and aluminum deposition (Figure 1f). A $L=4 \mu \mathrm{m} w=0.2 \mu \mathrm{m}$ beam with a $d=100 \mathrm{~nm}$ gap is shown in Figure 2. Several dimensions are available to demonstrate multi frequency possibilities on a same chip in the $10-500 \mathrm{MHz}$ range.

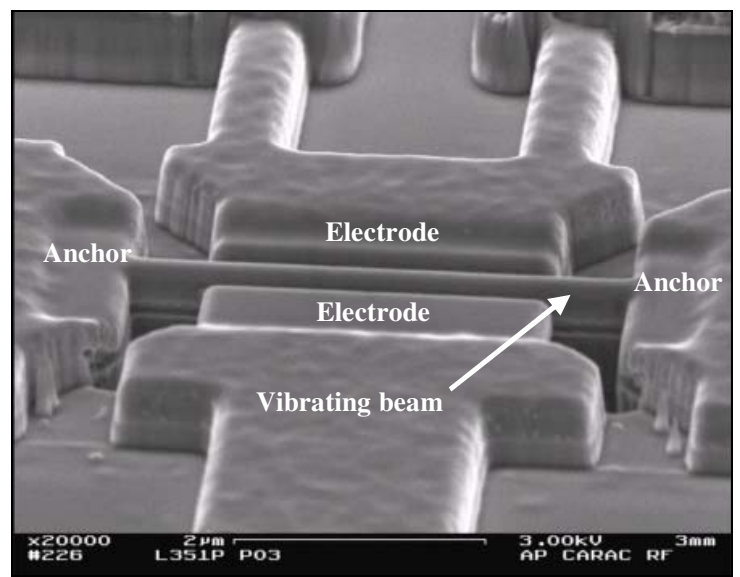

Figure 2: Perspective SEM picture of a clamped-clamped beam $(L=4 \mu \mathrm{m}, w=0.2 \mu \mathrm{m}$ and $d=100 \mathrm{~nm})$

\section{MEASUREMENT SET-UP}

RF characterizations are performed using a HP8753D network analyzer as depicted in Figure 3. The transmitted signal through the resonator is measured between the vibrating beam and the input port of the device. A bias voltage $V_{P}$ is applied on the input port; the beam and the substrate being grounded to avoid any pull-in effect of the structure with the substrate.

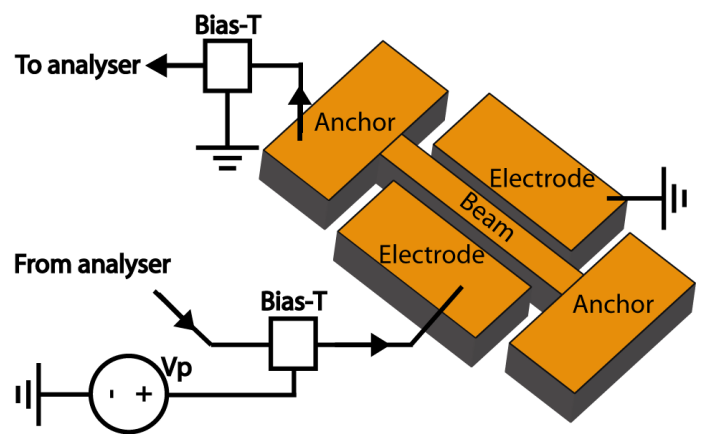

Figure 3: Schematic of the electrical characterization set-up (All tests were performed with devices under a vacuum chamber)

\section{ELECTRICAL EQUIVALENT CIRCUIT}

We consider a device based on a clamped-clamped (CC) beam with the following dimensions: $L=4.9 \mu \mathrm{m}$, $w=0.26 \mu \mathrm{m}$ and $d=95 \mathrm{~nm}$. We propose in Figure 4 an equivalent circuit of the device around the first resonance mode of the beam. The circuit will be then used in the ADS software to simulate the frequency response of the device.

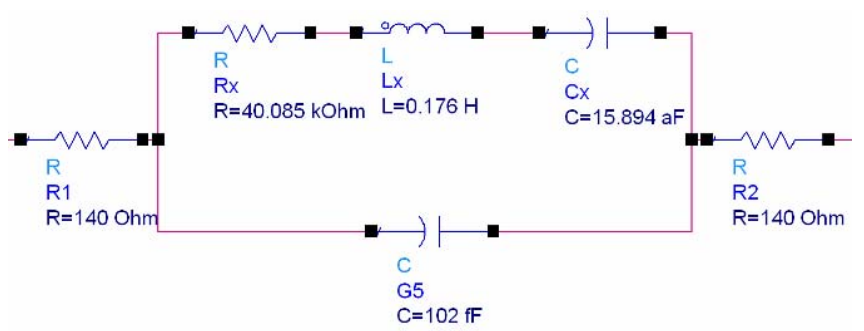

Figure 4: Electrical equivalent circuit of the device dynamic response around the resonance frequency obtained on $A D S$

The electrical model is composed of two $140 \Omega$ access resistances in series, corresponding to the resistance of the electrical pads and the $10 \mu \mathrm{m}$ long doped silicon access lines. The two parallel branches [4] correspond respectively to the path of the motional current arising from the mechanical vibration of the beam, and to the path of the parasitic current induced by the direct capacitive coupling between the input and output of the device.

The motional branch is classically described as a series $R_{x} L_{x} C_{x}$ circuit where $R_{x}$ corresponds to the motional resistance. The electrical $R_{x} L_{x} C_{x}$ parameters are linked to mechanical properties of the device by the following relations:

$$
\begin{gathered}
R_{x}=\frac{\sqrt{k \cdot m}}{Q \cdot \eta^{2}}, L_{x}=\frac{m}{\eta^{2}}, C_{x}=\frac{\eta^{2}}{k} \\
\text { with } \eta=\frac{V_{p} \varepsilon_{0} S}{d_{0}^{2}}
\end{gathered}
$$

$m$ and $k$ are respectively the effective mass and effective stiffness of the resonating beam for the vibration mode under consideration, $Q$ the quality factor, $\eta$ the electromechanical coupling, $V_{p}$ the bias voltage, $\varepsilon_{0}$ the permittivity, $S$ the surface, $d_{0}$ the initial gap. Simulations were performed using the following values: $R_{x}=40.085 \mathrm{k} \Omega$, $L_{x}=0.176 \mathrm{H}, C_{x}=15.894 \mathrm{aF}$.

The second branch is composed of a capacitance. This branch corresponds to the path of the direct coupling parasitic current that is superimposed to the motional current. It induces an anti-resonance peak in the electrical frequency response of the device. The Value for simulation was the following: $C_{0}=102 \mathrm{fF}$. 


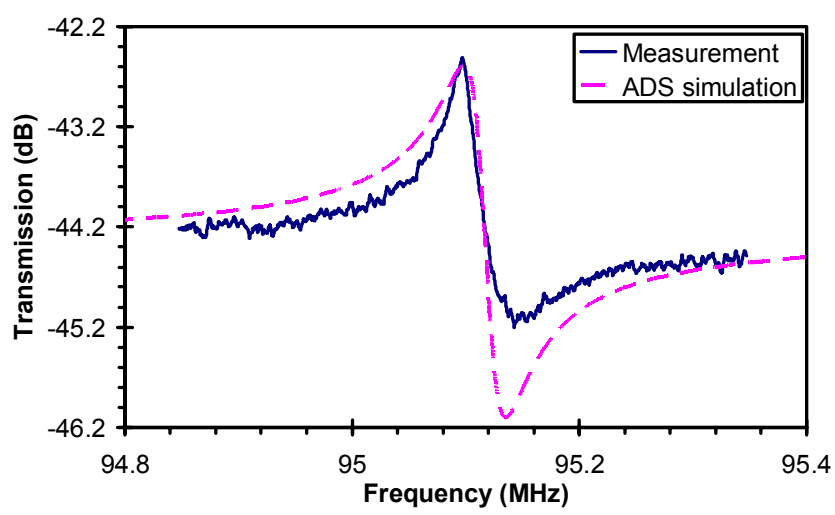

Figure 5: Frequency response comparison of electrical ADS simulation and device measurement on a clamped-clamped beam resonator $(L=4.9 \mu \mathrm{m}, w=0.26 \mu \mathrm{m}$ and $d=95 \mathrm{~nm})$

Figure 5 shows a comparison between the electrical ADS simulation based on the electrical circuit of Figure 4 and the frequency response of the device around the fundamental resonance frequency. The transmission peak is in good correlation with measurement as well as the antiresonance peak shape and frequency. Work is in progress to improve simulations so as to be able to better predict the electrical responses for future devices fabrication.

\section{EXPERIMENTALS RESULTS}

\section{Devices dynamic electrical responses}

Beam structures with dimensions $L=4$ to $10 \mu \mathrm{m}$ and $w=0.2$ to $0.5 \mu \mathrm{m}$ have shown resonance frequencies from 15 to $100 \mathrm{MHz}$ for the fundamental mode of vibration under vacuum.

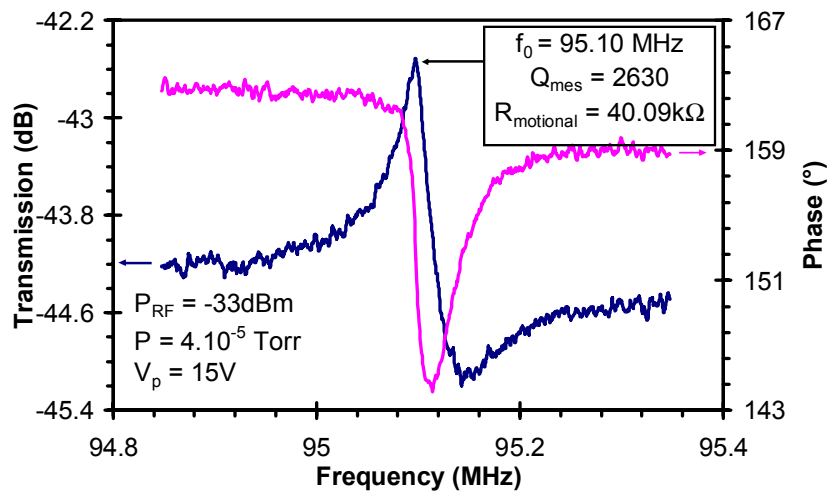

Figure 6: Frequency and phase response measured on a clamped-clamped beam resonator $(L=4.9 \mu \mathrm{m}, w=0.26 \mu \mathrm{m}$ and $d=95 \mathrm{~nm}$ )

Figure 6 gives the transmission and phase response of a clamped-clamped beam $(L=4.9 \mu \mathrm{m}, w=0.26 \mu \mathrm{m}, d=95 \mathrm{~nm})$. The fundamental resonance was measured at $95.10 \mathrm{MHz}$ for $V_{p}=15 \mathrm{~V}$. This is in good agreement with analytic calculations that give $94.71 \mathrm{MHz}$ and FEM simulations with 93.90MHz. A motional resistance of $40 \mathrm{k} \Omega$ was extracted from measurements. As quality factor of 2630 under vacuum was calculated from the measured response, considering the bandwidth at the middle height of the peak. The quality factor was also estimated by analytical calculation as detailed in [5] for the same structure. The analytical calculations give a quality factor of 3015 , with a limitation due to support losses. This is in good correlation with measurement. Only a 15\% discrepancy between calculation and measurements is observed, probably due to some losses not taken into account in calculations.

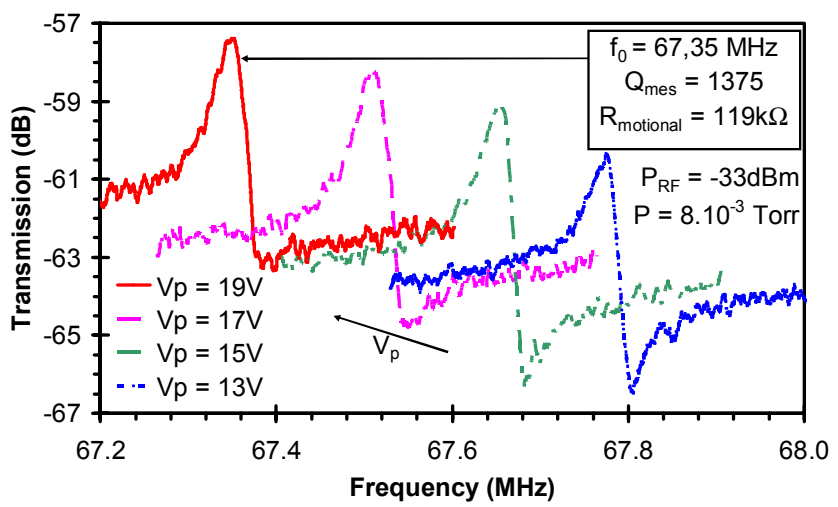

Figure 7: Frequency response measured on a clampedclamped beam resonator as a function of $V_{p}(L=5.0 \mu \mathrm{m}$, $w=0.19 \mu \mathrm{m}$ and $d=110 \mathrm{~nm})$

Figure 7 gives four resonance curves versus $V_{p}$ for a clamped-clamped beam $(L=5.0 \mu \mathrm{m}, w=0.19 \mu \mathrm{m}, d=105 \mathrm{~nm})$. The fundamental resonance was measured at $67.35 \mathrm{MHz}$ for $V_{p}=19 \mathrm{~V}$. This is in good agreement with analytic calculations that give $66.47 \mathrm{MHz}$ and FEM simulations with $67.86 \mathrm{MHz}$. A quality factor $Q$ of 1375 and a motional resistance of $119 \mathrm{k} \Omega$ are obtained under vacuum. The resonance frequency shifts linearly with $V_{p}^{2}$ with a tuning range better than $1 \%$. This enables a frequency tuning for temperature, process or aging compensation for time reference perspectives. An effective gap value of $150 \mathrm{~nm}$ was extracted from measurements of the resonance frequency shift as a function of $V_{p}$ (curves Figure 7).

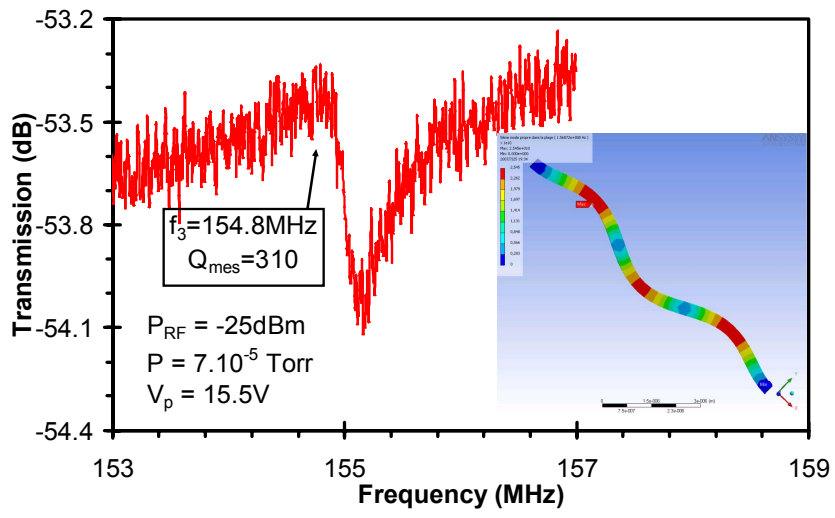

Figure 8: Frequency response showing the third resonance mode of a clamped-clamped beam resonator $(L=10 \mu \mathrm{m}$, $w=0.35 \mu \mathrm{m}$ and $d=115 \mathrm{~nm}$ )

We also observed third order resonances on a clampedclamped beam $(L=10 \mu \mathrm{m}, \quad w=0.35 \mu \mathrm{m}, \quad d=115 \mathrm{~nm})$. The 
fundamental and third order modes are respectively at $29.7 \mathrm{MHz}$ and $154.8 \mathrm{MHz}$ (Figure 8), in good agreement with FEM simulations giving 156.9MHz.

\begin{tabular}{|c|c|c|c|c|c|}
\hline $\begin{array}{c}\text { Dimensions } \\
\mu \mathrm{m}\end{array}$ & $\begin{array}{c}f_{0 \text { meas }} \\
\mathrm{MHz}\end{array}$ & $\begin{array}{c}f_{\text {0ana }} \\
\mathrm{MHz}\end{array}$ & $Q_{\text {meas }}$ & $\begin{array}{c}R_{m} \\
\mathrm{k} \Omega\end{array}$ & $\begin{array}{c}V_{p} \\
\mathrm{~V}\end{array}$ \\
\hline $\begin{array}{c}4.9 \times 0.26 \\
d_{0}=95 \mathrm{~nm}\end{array}$ & 95.10 & 94.71 & 2630 & 40 & 15 \\
\hline $\begin{array}{c}5.0 \times 0.19 \\
d_{0}=110 \mathrm{~nm}\end{array}$ & 67.35 & 66.47 & 1375 & 119 & 19 \\
\hline
\end{tabular}

Table 1: RF characteristics of the presented devices

Table 1 resumes the RF characteristics of the devices.

\section{Resonators behavior with environment}

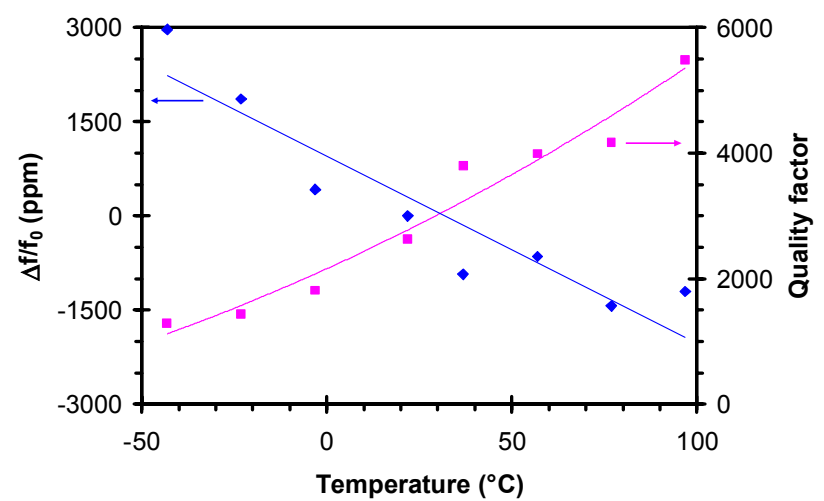

Figure 9: Measured effects of temperature on resonance frequency and $Q$ factor of a clamped-clamped beam resonator $(L=4.9 \mu \mathrm{m}, w=0.26 \mu \mathrm{m}$ and $d=95 \mathrm{~nm})$

Figure 9 shows the effects of temperature on both resonant frequency and quality factor for a clampedclamped beam resonator. The study was made on a $150^{\circ} \mathrm{C}$ temperature range (from $-50^{\circ} \mathrm{C}$ to $100^{\circ} \mathrm{C}$ ), corresponding to specifications for cellular phones.

The resonant frequency shifts down quasi-linearly with temperature, leading to an average of $-32 \mathrm{ppm} /{ }^{\circ} \mathrm{C}$, without any compensation. The negative frequency shift when temperature is growing up is attributed to the negative stiffness induced by the beam elongation, implying a compressive stress. We calculated that a $V_{p}$ variation of $2.5 \mathrm{~V}$ is enough to compensate the frequency shift in a $100^{\circ} \mathrm{C}$ temperature range. This electrical tuning could be used to compensate the frequency shift for time reference applications.

Figure 9 also shows that the quality factor is growing up with temperature, from 1300 at $-40^{\circ} \mathrm{C}$ to 5500 at $100^{\circ} \mathrm{C}$ $\left(2630\right.$ at $\left.23^{\circ} \mathrm{C}\right)$. We think that this tendency could be attributed to the residual stress on the structure at ambient temperature. When temperature is growing up, the induced stress can compensate the residual stress and limit losses. We suppose that a maximum of quality factor can be observed at higher temperatures than $100^{\circ} \mathrm{C}$ when the induced stress due to temperature will compensate a maximum of residual stress. More measurements should be investigated to verify this hypothesis.

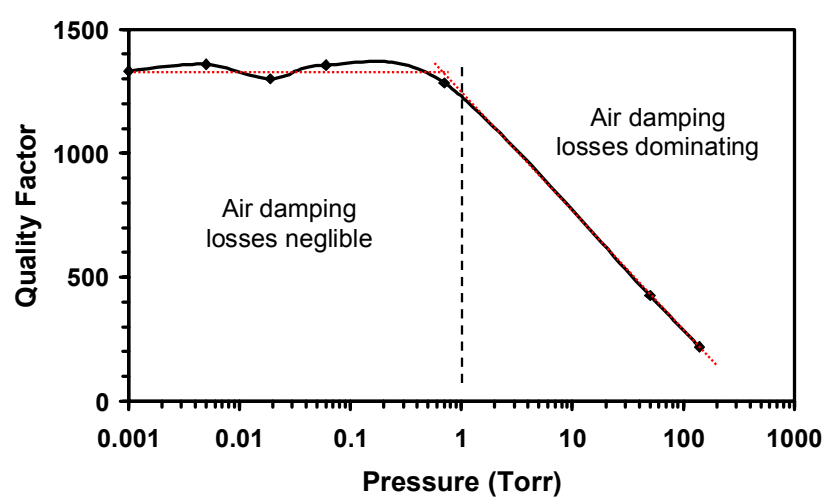

Figure 10: Evolution of $Q$ as a function of pressure for a $C C$ beam resonator $(L=5.0 \mu \mathrm{m}, w=0.19 \mu \mathrm{m}$ and $d=110 \mathrm{~nm})$

Figure 10 shows quality factor dependence on the pressure extracted from measurements. It varies from 1330 under vacuum to 220 at 140 Torr. Even with small beam dimensions, air damping is still the major contributor of energy losses when working at higher pressure than 1 Torr.

\section{CONCLUSION AND PERSPECTIVES}

In-IC nanometer scale resonators have been fabricated using SON technology on 8 inch wafers, and successfully characterized up to $154 \mathrm{MHz}$, with a study of temperature and pressure effects on resonators.

Future work will focus on improving the $f . Q$ product and the low voltage operation of the resonators, improving the output detection by the use of integrated MOSFET transistors [6], and working on in-IC integration of devices.

\section{ACKNOWLEDGMENT}

The authors wish to acknowledge Daniel Grogg and Adrian Ionescu from EPFL for their collaboration on temperature measurements, made in their laboratory.

\section{REFERENCES}

[1] S. Monfray et al., Technical Digest International Electron Devices Meeting, Washington DC, USA, December 3-5, 2001, pp. 29.7.1 - 29.7.4.

[2] C.T.-C. Nguyen, Proceedings of the $13^{\text {th }}$ IEEE International Conference On Solid-state Sensors, Actuators and Microsystems Transducers'05, Seoul, Korea, June 5-9, 2005, pp. 243-246.

[3] C. Durand et al., Symposium on Design Test Integration Packaging of MEMS/MOEMS, Stresa Lago Maggiore, Italy, April 25-27, 2007, pp. 326-331.

[4] J. R. Clark et al., Proceedings of the $11^{\text {th }}$ IEEE International Conference On Solid-state Sensors, Actuators and Microsystems Transducers'01, Munich, Germany, June 10-14, 2001, pp. 1118-1121.

[5] Z. Hao et al., Sensors and Actuators, A 109, 2003, pp. 156-164.

[6] D. Grogg et al., Proceedings of the $14^{\text {th }}$ IEEE International Conference On Solid-State Sensors, Actuators and Microsystems Transducers'07 and Eurosensors, Lyon, France, June 10-14, 2007, pp. 1709-1712. 